\title{
Prospek Kakao Nasional dalam Perspektif Kebijakan
}

\author{
Frederik Depparaba ${ }^{1}$, Harli A. Karim ${ }^{2}$ \\ Program Studi Agroteknologi, Fakultas Pertanian, Universitas Al Asyariah Mandar \\ harlipertanian@gmail.com
}

\begin{abstract}
Abstrak
Perhatian Pemerintah terhadap usahatani kakao cukup besar, hal ini tercermin dengan diselenggarakannya program dan proyek dan didukung sejumlah lembaga penelitian dan lembaga lainnya yang tertujuan untuk meningkatkan produktivitas dan produksi kakao nasional. Kakao nasional berada pada urutan ke-2 penghasil kakao dunia setelah Pantai Gading, Afika Barat, suatu capaian produksi yang signifikan sebagai penghasil devisa utama dalam ekspor komoditi perkebunan. Meskipun dalam tahun 2018 terdapat penurunan produksi kakao nasional karena berbagai faktor teknis, non teknis, dan produktivitas fluktuatif, namun itu tidak menjadi kendala dalam upaya peningkatan produktivitas dan produksi kakao nasional ke depan, dengan harapan kendala teknis dan non teknis dapat diatasi dengan dukungan berbagai pihak yang terkait dengan industri kakao nasional.
\end{abstract}

Keywords : Prospek, Kakao Nasional, Perspektif, Kebijakan

\section{Pendahuluan}

Perhatian pemerintah terhadap usaha pengembangan perluasan areal tanam dan peningkatan produksi dan mutu kakao cukup besar, hal ini tercermin dengan dibentuknya lembaga pusat penelitian kakao dan lembaga penelitian lainnya, diselenggarakannya beberapa program dan proyek yang bertujuan untuk meningkatkan produktivitas dan produksi kakao nasional.

Pengembangan perluasan areal tanam dan peningkatan produksi tersebut telah membentuk apa yang disebut "sabuk hijau kakao" atau dikenal dengan sebutan "cacao belt". Istilah klasik pengembangan dan perluasan areal tanam kakao disebut sentra-sentra pengembangan dan produksi kakao. Istilah klasik tersebut sesungguhnya berujung pada pemahaman "cacao belt". Luas areal versi kompas 7 Nopember 2013 adalah 1,6 juta ha, sebagian besar adalah perkebunan rakyat.

Macam-macam program dan proyek yang telah dilakukan untuk menunjang produktivitas dan produksi kakao nasional, mulai dari perluasan areal tanam, sekolah lapang pengendalian hama terpadu (SL-PHT), pilot-pilot proyek yang telah dilakukan oleh sejumlah lembaga penelitian dan kegiatan yang masih hangat dalam pikiran kita adalah proyek gerakan nasional peningkatan produksi dan mutu kakao yang dikenal dengan nama "Gernas Pro Kakao" tahun 2009-2014.

Dampak program dan proyek tersebut adalah Indonesia telah berhasil sebagai produsen kakao dunia enempati urutan kedua setelah Pantai Gading, menyusul Ghana, Negeria dan Camerun Afrika (FAO STATE DATE, 2013). Namun harapan untuk menggeser Pantai Gading Afrika sebagai penghasil kakao dunia cenderung belum memenuhi harapan karena produksi fluktuatif, bahkan menurun sejak tahun 2014-2017 sebagaimana berita harian Kompas 17 Februari 2018, hingga Indonesia mengimpor biji kakao dari luar negeri terutama dari Pantai Gading, Ghana, Kamerun (Afrika), dan Ekuador (Amerika Selatan), meskipun data tahun
2016-2017 adalah angka sementara dan estimasi versi Kompas 17 Februari 2018. Untuk itu upaya untuk meningkatkan produksi kakao nasional sangat diharapkan.

\section{Sentra Produksi}

Sentra produksi dalam arti klasik adalah pusatpusat produksi kakao yaitu wilayah pengembangan produksi di Indonesia, meliputi 25 propinsi yang pernah tergabung dalam program gerakan nasional peningkatan produksi dan mutu kakao dengan singkatan "gernas pro kakao". Ke-25 propinsi tersebut versi Anonim,t.t. antara lain adalah Sulawesi Selatan, Sulawesi Barat, Sulawesi Tenggara, Sulawesi Tengah, Gorontalo, Sulawesi Utara, Maluku, Papua, Papua Barat, NTT, NTB, Bali, Kalimantan Timur, Kalimantan Selatan, Sumatera Utara dan beberapa wilayah di pulau Jawa. Dimana produksi kakao nasional umumnya dari kawasan timur Indonesia dan Sulawesi sebagai sentra produksi.

Pulau Sulawesi merupakan sentra produksi kakao nasional dan sekitar $73 \%$ dari seluruh kakao nasional dihasilkan dari wilayah ini (Anonim,2011). Sentra produksi tersebut didukung 99\% area kakao di Sulawesi yang merupakan perkebunan rakyat versi ACDI/VOCA (2001), terbentang dari Sulawesi Tenggara ke Sulawesi Selatan ke Sulawesi Barat ke Sulawesi Tengah hingga Gorontalo dan Sulawesi Utara, yang telah membentuk jalur coklat pengembangan kakao (Cacao Belt) untuk tujuan produksi seperti tergambar pada peta sentra produksi kakao di pulau Sulawesi. 


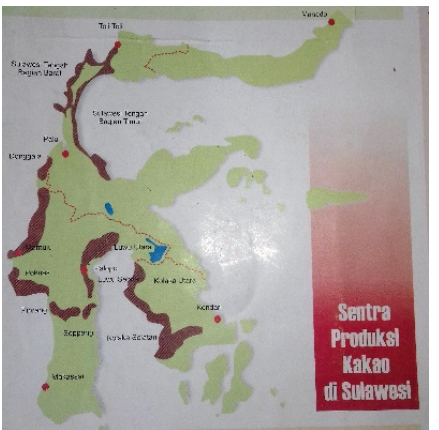

\section{Peta Sentra Produksi Kakao Sulawesi (ACDI/VOCA, 2001)}

Kakao Sulawesi salah satu komoditas andalan yang dapat menghasilkan devisa utama dan dapat memperbaiki pendapatan dan kesejahteraan petani apabila produktivitas/produksi terus meningkat.

Cacao belt yang terbentuk di sentra produksi kakao Sulawesi seperti tergambar pada peta, merupakan niche perkembangbiakan hama dan penyakit kakao karena tersedia habitat sepanjang tahun, sebagai salah satu factor pembatas dan kendala dalam peningkatan produksi. Beberapa laporan yang pernah ada perihal wabah hama PBK di Sulawesi, sehingga berbagai upaya telah dilakukan untuk pemberantasannya. ACDI/VOCA, sebuah organisasi non profit pengembangan internasional yang berkedudukan di Amerika, Washington DC, pernah membantu dalam pemberantasan PBK untuk tujuan peningkatan produksi kakao di Sulawesi melalui Success Project. Kegiatan organisasi non profit tersebut dengan Success Project Sulawesi adalah untuk meningkatkan penghasilan petani kakao di Indonesia dengan mengurangi kerusakan yang diakibatkan hama PBK, sehingga produktivitas dan produksi kakao dapat ditingkatkan dengan harapan dapat mejadi Negara penghasil kakao dunia.

Data yang telah dirilis FAO STATE DATA 2013 (FSD, 2013) mengenai Negara-negara potensial kakao dunia berturut-turut adalah Pantai Gading (Afrika) 1.559.441 ton/tahun, Indonesia 712.200 ton/tahun, Ghana (Afrika) 700.020 ton/tahun, Nigeria (Afrika) 400.000 ton/tahun, dan Cameron (Afrika) 272.000 ton/tahun. Berdasarkan data yang telah dirilis Word Cacao Foundation 2011 bahwa negara-negara penghasil kakao didunia didukung oleh sejumlah petani kakao di dunia mencapai 5-6 juta petani, dimana 40-50 juta orang bergantung pada kakao sebagai mata pencaharian. Berdasar data tersebut, Indonesia berada pada urutan kedua penghasil kakao dunia, hal ini tentu ada hubungannya dengan sentra-sentra produksi kakao dan program-program pemerintah yang berhubungan dengan pengembangan produksi kakao nasional. Harapan yang kelak diharapkan adalah Indonesia berpeluang sebagai Negara penghasil kakao terbesar dunia yang mungkin saja dapat menggeser Pantai Gading Afrika.

\section{Kendala Produksi}

Beberapa upaya telah dilakukan untuk meningkatkan produktivitas dan produksi kakao nasional antara lain adalah "gernas pro kakao", namun suasana di medan pengembangan dan produksi menghadapi kendala antara lain adalah serangan hama PBK, pemeliharaan yang tidak intensif, iklim dan cuaca yang senantiasa berubah-ubah.

Iklim yang kurang bersahabat misalnya hembusan angin kencang, curah hujan yang tinggi memicu penyakit busuk buah (Phytopthora Spp), munculnya daun-daun muda seraya buah-buah muda berguguran (Cherelle wilt), karena sifat fisiologis tanaman kakao. Suatu konsepsi fisiologis tanaman kakao versi Susanto (2003) bahwa dalam satu pohon kakao dapat menghasilkan \pm 10.000 kuntum bunga setiap tahun, namun yang berhasil tumbuh dan berkembang menjadi buah-buah muda hanya 10-50 bunga saja, karena terjadi persaingan dalam penyerapan hara antara daun-daun muda dan kuntum-kuntum bunga, sehingga pemeliharaan tanaman secara intensif melalui pemangkasan, sabaiknya dilakukan paling lambat 1 (satu) bulan sebelum terbentuk kuntum-kuntum bunga atau pemangkasan produksi yang ringan saja. Pemeliharaan tersebut akan lebih permanen bila dilakukan peremajaan, rehabilitasi dan intensifikasi sebagaimana panduan teknis budidaya kakao dari Direktorat Jenderal Perkebunan (2009).

Kendala lain dalam upaya peningkatan produktivitas dan produksi kakao nasional adalah panen yang tidak serentak sehingga produktivitas fluktuatif. Mengingat gernas pro kakao meliputi kegiatan peremajaan, yaitu mengganti tanaman yang rusak dan sudah tua, rehabilitasi tanaman yang tidak produktif melalui teknik sambung samping dan intensifikasi melalui teknis budidaya, sehingga ada tenggang waktu sejak kegiatan dimulai hingga tanaman mulai berproduksi. Tenggang waktu tersebut dapat membatasi produksi.

Selanjutnya, areal tanaman kakao yang telah membentuk jalur coklat pengembangan produksi (Cacao Belt) seperti pada peta di pulau Sulawesi, merupakan salah satu sebab PBK dapat menjadi wabah yang dapat menurunkan produktivitas hingga $80 \%$ dari potensi produksi, sehingga dapat pula mempengaruhi produksi kakao nasional. Wabah PBK versi ACDI/VOCA (2001) pernah terjadi tahun 1991 di areal perkebunan rakyat di Sulawesi yang menyebabkan kerusakan serius buah-buah kakao pada waktu itu. Jalur coklat yang terbentuk itu merupakan habitat dan niche PBK yang tersedia sepanjang tahun sebagai tempat berlindung dan melangsungkan kehidupannya sambil menunggu tersedianya buah-buah kakao untuk diserang. Medan pengembangan produksi seperti ini dapat pula sebagai basis perkembangbiakan dan penyebaran hama tersebut.

Perlu diketahui bahwa sepak terjang hama PBK adalah sebagai serangga hama spesialis ada dimanamana, pewaris genetic rasbiologi untuk beradaptasi, perkembangbiakannya mudah dan cepat, mudah menyebar, mudah menemukan buah-buah kakao untuk diserang, dapat diduga bahwa serangga hama tersebut 
berstrategi " $r$ ". Oleh karena itu, hama tersebut harus dihadapi dengan cara spesialis pula. Pemahaman selama ini bahwa pemencaran hama PBK dapat melalui benih atau bibit yang telah terdapat kepompong atau pupa sebagai silent pest, tidak sehebat pemahaman bahwa PBK ada dimana-mana, hidup diberbagai daerah pengembangan sebagai hama endemic (native pest) yang merusak buah-buah kakao dan pindah ke tanaman inang alternative manakala buah-buah kakao tidak tersedia di kebun.

Suatu pemahaman dan pengetahuan yang mendasar baik itu sebagai PBK imigran dari luar wilayah Indonesia sebagai "alien pest" maupun PBK yang asli di suatu wilayah pengembangan sebagai "native pest" atau disebut juga sebagai PBK endemic. Pengetahuan ini didasari bahwa terdapat berbagai spesis PBK versi Bradley (1986) dan Tay and Bong (2000.

PBK imigran dan PBK endemic bisa saja bergabung dalam suatu wilayah pengembangan karena pemencaran atau penyebaran hama tersebut, dan berkembangbiak di wilayah tersebut sehingga dapat mejadi wabah karena terjadi kelimpahan populasi. Kelimpahan populasi disuatu wilayah didukung studi kelimpahan dan penyebaran populasi yang sudah cukup lama diselidiki dan dipelajari oleh Andrewartha dan Birch (1954).

Pengetahuan dan pemahaman perihal PBK imigran dan PBK endemic diperlukan suatu identifikasi yang didasari identifikasi PBK oleh Bradley (1986) melalui Description of Three Allied News Spesies dan Management of Cocoa Pest oleh Tay and Bong (2000), dengan tetap mempelajari ekologi hama tersebut.

Melalui pengetahuan dasar mengenai identifikasi dan ekologi PBK, kemudian dapat dirangkum suatu metode pemberantasan hama tersebut dengan memanfaatkan petani bermotivasi kuat untuk dijadikan ahli pemberantasan partisipatif yang merupakan tindak lanjut beberapa hasil penelitian oleh para ahli entomologi yang pernah ada.

Kelak, para petani yang sudah memahami caracara pemberantasan dengan motivasi kuat dan memiliki kosmovisi yang handal, dapat dijadikan sebagai "former to former extension" versi Anonim (1977) untuk menyebarluaskan pengetahuan tersebut kepada sesama petani dalam menghadapi serangan $\mathrm{PBK}$.

\section{Harapan ke Depan}

Beberapa kendala peningkatan produktivitas/ produksi kakao yang disebutkan sebagai penyebab produktivitas/produksi menurun, sehingga impor kakao dari luar negeri tidak bisa dihindari. Impor kakao sebagaimana pemberitaan Kompas 17 Februari 2018 terutama dari Pantai Gading dan Cameron (Afrika) dan Ekuador (Amerika Selatan) untuk memenuhi kapasitas industry pengolahan kakao yang mencapai 800.000 ton/tahun, sementara pasokan kakao domestic (dalam negeri) hanya 250.000 ton/tahun. Impor kakao tersebut melonjak $270 \%$ dari 61.000 ton tahun 2016 menjadi 226.000 ton tahun 2017, sementara industry kakao semakin bergantung pada kakao impor, karena produktivitas/produksi kakao dalam negeri terus menurun. Penurunan produktivitas/produksi kakao nasional versi Kompas 17 Februari 2018 yaitu produktivitas turun dari $821 \mathrm{~kg} /$ ha tahun 2013 menjadi $775 \mathrm{~kg} / \mathrm{ha}$ tahun 2015 dan $787 \mathrm{~kg} / \mathrm{ha}$ tahun 2017, sedangkan produksi nasional turun dari 720.862 ton tahun 2013 menjadi 593.331 tahun 2015 dan 688.345 ton tahun 2017. Meskipun tahun 2016 dan 2017 adalah angka estimasi versi Kompas 17 Februari 2018.

Produksi kakao nasional yang semakin menurun, ada hubungannya dengan produktivitas/ produksi yang tidak serempak untuk seluruh daerah pengembangan produksi di Indonesia, sebab produksi kakao nasional umumnya diproduksi dari kawasan timur Indonesia dimana Sulawesi sebagai sentra produksi kakao nasional. Suatu analisis bahwa impor kakao bisa saja ditiadakan apabila produktivitas/produksi kakao nasional serempak di seluruh daerah pengembangan yang pernah tergabung dalam gernas pro kakao yaitu 25 provinsi. Tidak serentaknya produksi di semua daerah pengembangan produksi dapat menyebabkan produksi fluktuatif sehingga pasokan dalam negeri terbatas dan impor kakao tidak dapat dihindari, belum termasuk bila ada masalah teknis dan non teknis lainnya di masingmasing daerah pengembangan.

Dalam hubungan ini, sebagaimana berita Kompas 17 Februari 2018 pelaku usaha berharap agar pemerintah mamacu produksi di hulu dan menghapus hambatan di hilir agar produk olahan tetap kompetitif. Hilirisasi industry berbasis agro (pertanian) di Indonesia belum optimal, senergi sector pertanian sebagai penyedia bahan baku dan sector industry sebagai pengguna bahan baku dan dukungan sector jasa dibutuhkan untuk mendukung keberlanjutan industry pertanian.

Harapan pelaku usaha terhadap pemerintah tentu berujung pada kebijakan/keputusan. Dikalangan penentu kebijakan/keputusan dalam masalah impor kakao, ada kata-kata "koordinasi dan kerjasama antar semua lembaga terkait" yang dapat membantu dalam memperbaiki produksi kakao nasional. Kerjasama antar lembaga versi ACDI/VOCA (2001) mungkin dengan Pusat Pengembangan Bersama Kakao (CCDC), Dinas Perkebunan, Askindo, ICCRI di Indonesia dan mitra internasional seperti ACRI dari USA, CIRAD dari Perancis, BCCCA dari Inggris dan Departemen Pertanian Amerika Serikat (USDA) yang mungkin dapat sebagai pendonor dalam pelaksanaan kegiatan proyek. Dengan dukungan dan mitra yang begitu luas diharapkan dapat membantu petani dan memperbaiki produksi kakao nasional, dengan harapan di tahun 2020 Indonesia bisa menjadi produsen kakao terbesar dunia, mengingat luas areal tanaman kakao versi Kompas 7 Nopember 2013 adalah 1,6 juta ha, dapat memenuhi target produksi 1,7 juta ton pertahun bilamana ada komitmen antara pemerintah, pengusaha dan petani untuk mencapai target tersebut. Dalam hubungan kerjasama ini, pihak Barry Callebaut Group (BCG) suatu produsen coklat dan produk biji kakao terbesar dunia pernah mengungkapkan bahwa tahun 2020 akan membina petani kakao di Indonesia, suatu harapan yang menjanjikan yang diharapkan dalam upaya perbaikan masa depan kakao nasional. 
Selanjutnya, jika impor kakao hanya digunakan sebagai pencampur untuk mendapatkan aroma dan tekstur cokelat tertentu, apakah kakao dalam negeri tidak bisa seperti itu? sementara Indonesia termasuk eksportir ketiga terbesar dunia, hasil kerja berat dari ribuan petani kecil dan mengapa sampai terjadi impor ? Kakao merupakan mata pencaharian bagi petani kecil di Indonesia, yang mengharapkan kehidupan dan masa depan dari lapangan kerja sector perkebunan kakao, semoga harapan ini dapat memberi motivasi yang kuat bagi petani.

\section{Kesimpulan}

Pengembangan dan perluasan areal tanam hingga mencapai 1,6 juta ha pernah dilakukan diberbagai daerah pengembangan dengan berbagai program dan proyek untuk meningkatkan produktivitas dan produksi kakao nasional.

Dampak program dan proyek peningkatan produktivitas dan produksi, Indonesia telah berhasil sebagai produsen kakao dunia menempati urutan kedua setelah Pantai Gading Afrika. Namun akhir-akhir ini produktivitas dan produksi kakao nasional mengalami penurunan karena menghadapi berbagai kendala antara lain adalah serangan hama PBK, pemeliharaan yang tidak intensif, iklim yang senantiasa berubah-ubah dan sejumlah kendala teknis dan non teknis lainnya.

Koordinasi dan kerjasama antar lembaga terkait diharapkan dapat membantu dalam memperbaiki produktivitas dan produksi kakao nasional dengan harapan impor ditiadakan dan ekspor kakao nasional dapat berjalan sesuai yang diharapkan dan kehidupan petani kecil yang hidup dari sector perkebunan kakao dapat berlangsung sesuai harapan mereka.

\section{Daftar Pustaka}

Andrewartha, H.G. and L.C. Birch. 1954. The Distributions and Abudance of Animals. The University of Chicago Press. 782 pp.

Anonim. 1977. Farmer-Led Extension : Consepts and Practicess. Intermediate Technology Publications Ltd, 103-105. Southampton Rows, London WCIB 4 $\mathrm{HH}, \mathrm{UK}$, in Association with International Institute of Rural Reconstruction, Silang, Cavite 4118, Philippiness ; Overseas Development Institute, London, UK ; Word Neighbors, Oklahoma City, OK, USA. P-214.

ACDI/VOCA. 2001. News Letter Success Project Sulawesi. Sustainable Cocoa Extension Service for Smallholders. 4 hal.

Anonim. 2011. Sulbar siap sukseskan Gernas Pro Kakao, dalam Buletin Infokom Gerbang Sulbar, Edisi Perdana Maret 2011. Hal 6-7.

Bradley, J.D. 1986. Identity of The South-East Asian Cocoa moth Conopomorpha Cramerella (Smellen) (Lepidoptera ; Gracillariidae) with Description of Three Allied News Spesies. Bulletin of Entomological Research. $76: 41-51$.

Susanto, F.X. 2003. Tanaman Kakao : Budidaya dan Pengolahan Hasil. Penerbit Kanisius Yogyakarta. 183 hal.

Tay, E.B. and C.L. Bong. 2000. Management of Cocoa Pest and Diseases in Malaysia in The year 2000, in pest Management and The Environment in 2000, $\mathrm{CAB}$ International in Assosiation with The Agricultural Institute of Malaysia. P.231-249. 